\title{
Clinical efficacy of the therapeutic interventions for actinic prurigo. A systematic review
}

\section{Eficacia clínica de intervenciones terapéuticas para prurigo actínico. Una revisión sistemática}

\author{
Laura E. Domínguez-Gallegos ${ }^{1}$, Martha A. Morales-Sánchez ${ }^{1}$, Fermín Jurado-Santa Cruz ${ }^{1}$ y \\ Josué E. Villegas-Domínguez ${ }^{2 *}$ \\ ${ }^{1}$ Dermatological Center "Ladislao de la Pascua", Mexico City; 2Public Health Department, Medical School, Universidad del Valle de México, Veracruz, \\ Veracruz. Mexico
}

\begin{abstract}
Antecedents: Actinic prurigo is a rare idiopathic photodermatosis that has a markedly negative impact on the patients' quality of life. Several therapeutic strategies are available for actinic prurigo; these strategies are aimed at controlling the patient's lesions and associated symptoms, mainly by preventing exposure to the sunlight. Therefore, this review presents an evidence-based summary of the treatment options complementary to photoprotection for actinic prurigo. Objetive: to determine the efficacy and safety of the treatment options complementary to photoprotection for patients with AP and to assess the consistency of the findings and quality of the different studies included in this review. Material and metodh: The main electronic databases were searched for studies published up to 2018 using the search terms "actinic prurigo,"'actinic dermatitis," and "solar prurigo"; seven articles about therapeutic interventions, including clinical trials, quasi-experimental studies, and cohort studies were identified. Results and conclusion: According to evidence, thalidomide is an effective option, followed by phototherapy, pentoxifylline and ciclosporin; however, the quality of the evidence is poor in order to carry out a metanalysis or to identify the effectiveness of the treatments in a quantitative manner, therefore, clinical trials are required to obtain more precise values of efficacy of the treatment of actinic prurigo.
\end{abstract}

Keywords: Actinic prurigo. Photodermatosis. Therapeutic.

\section{Resumen}

Antecedentes: El prurigo actínico es una patología rara, idiopática, clasificada como la fotodermatosis con el mayor impacto negativo en la calidad de vida del paciente. Su tratamiento es variado y está dirigido a controlar las lesiones y los síntomas asociados, evitando principalmente el contacto con el sol, por lo que esta revisión presenta un resumen basado en la evidencia de las opciones complementarias a la fotoprotección. El objetivo de esta revisión es identificar la eficacia del tratamiento complementario a la fotoprotección en el prurigo actínico. Material y métodos: Se realizó una revisión sistemática en las principales bases de datos electrónicas de las publicaciones realizadas hasta el año 2018 con los términos "Actinic prurigo", "Actinic dermatitis" y "Solar prurigo". Se incluyeron siete artículos con diseño de ensayos clínicos, cuasiexperimentos y estudios de cohortes. Resultados y conclusión: Según la evidencia, la talidomida es una opción eficaz, seguida de fototerapia, pentoxifilina y ciclosporina. Sin embargo, la calidad de la evidencia es mala para realizar un metaa-

Correspondence:

*Josué E. Villegas-Domínguez.

E-mail: josue_eli@hotmail.com DOI: 10.24875/MCUT.21000005

0210-5187/C 2021 Colegio Ibero Latinoamericano de Dermatología A.C. (CILAD). Publicado por Permanyer. Este es un artículo open access bajo la licencia CC BY-NC-ND (http://creativecommons.org/licenses/by-nc-nd/4.0/). 
nálisis o identificar la efectividad de los tratamientos de manera cuantitativa, por lo que se requieren ensayos clínicos que permitan obtener valores más precisos de eficacia del tratamiento del prurigo actínico.

Palabras clave: Prurigo actínico. Fotodermatosis. Terapéutica.

\section{Introduction}

Actinic Prurigo (AP) is an idiopathic photodermatosis, so its presentation depends on the exposure to ultraviolet radiation. AP may develop at any age, appearing for first time more commonly during childhood ${ }^{1-4}$. Several factors are associated with the development of AP; however, the most important are genetic, age, female sex, living at a higher altitude $(1000 \mathrm{~m}$ above the sea level), level of education, duration of sun exposure, exposure to pets, and smoking ${ }^{5}$. AP is mainly prevalent in the native populations of the American continent and is not restricted to a single race. This disease predominantly affects the American Mestizo and Indian populations, with the Asian and European populations being less frequently affected ${ }^{2,3,6-9}$.

The pathophysiology of AP is not fully understood; however, the data available to date suggests that an autoimmune process is induced by ultraviolet $A$ and ultraviolet $B$ radiation, mainly-4,10. The prevalence of AP among ethnic groups can be explained due to its association with a specific type of major histocompatibility complex, such as HDL-DR4,which is present in $90 \%$ of the patients. In particular, the DRB1-0407 subtype is present in $60 \%$ of the patients in Mexico, Europe, and Canada. However, AP is most frequently associated with the Cw4, Cw3, and B40 subtypes among the Colombian patients $5,6,11,12$. AP, as an autoimmune disease, is not dose dependent, so a mild stimulus can trigger serious outcomes ${ }^{13}$.

The patients with AP present with distribution of the clinical features according to the body regions exposed to sunlight; symmetric and persistent lesions such as papules, xerosis, erosions, nodules, lichenification, hypo- or hyperpigmentation and scarring are observed in the ocular conjunctiva, lip mucosa, and skin; additionally, intense itching and excoriation are reported by the patients ${ }^{2}$.

The differential diagnosis of AP is mainly focused on acute idiopathic photodermatoses, such as Polymorphous Light Eruption and Atopic Dermatitis $1,2,10$.

The treatment modalities for patients with AP include physical protection like the use of photoprotective clothing, sunglasses, lip balms, and sunscreens with a sun protection factor greater than $30^{2,6,14-16}$, and simultaneous pharmacological treatment to reduce the patient's symptoms and a systemic treatment, being thalidomide the first-line drug, which was established in the 1970s. ${ }^{17}$. However, novel therapies, such as administration of psoralens followed by exposure to long-wave ultraviolet radiation, immunosuppressive therapy (such as cyclosporine or azathioprine), pentoxifylline, tetracyclines, vitamin $\mathrm{E}$, and $0.1 \%$ topical tacrolimus, are currently available $2,6,15,18-21$.

Of all the photodermatoses, AP has the greatest impact on the patient's daily life, on the Dermatology Life Quality Index (DLQI) questionnaire it has an average score of 13 points and it is the disease that more frequently scores $>10$ points; Therefore, personalizing the treatment and providing patients with the best options is extremely important ${ }^{22}$. This systematic review aimed to determine the efficacy and safety of the treatment options complementary to photoprotection for patients with AP and to assess the consistency of the findings and the quality of the different studies included in this review.

\section{Methods}

\section{Literature search and inclusion criteria}

A systematic review was conducted following the Preferred Reporting Items for Systematic Reviews and Meta-Analyses (PRISMA) guidelines between December 2018 and March 2019 through bibliographic databases, namely, MEDLINE, Cochrane, SciELO, and Google Scholar; experimental or quasi-experimental studies or prospective cohort studies on the treatment of AP that were published in any language until December 2018 were included. The search terms, "actinic prurigo" and "treatment", "actinic dermatitis" and "treatment", "solar dermatitis" and "treatment", "solar prurigo" and "treatment", "prurigo actínico" and "tratamiento", "prurigo solar" and "tratamiento", "dermatitis solar" and "tratamiento", and "dermatitis actínica" and "tratamiento", were selected from the Medical Subject Headings, and each article was approved by two reviewers. The main variables, which were established a priori, were the type of treatment as an independent variable and the efficacy and adverse reactions as dependent variables. 


\section{Data extraction}

Two researchers conducted an unblinded literature search and the inclusion of articles in the systematic review was decided in agreement with both the reviewers. In case of disagreement between the two researchers, a third reviewer voted to determine the inclusion of the article. At the end of the assessment, the selected articles were included in the systematic review, and the study variables were collected and classified according to their degree of evidence through the Grades of Recommendation Assessment, Development, and Evaluation (GRADE) system ${ }^{23,24}$.

\section{Assessment of the methodological quality}

The selected articles were assessed using the GRADE system, which indicated the quality of the evidence for a given outcome based on the study design. The GRADE system considered randomized clinical trials as a high-quality source and observational studies without significant limitations as a low-quality source. In systematic reviews, the assessment of the factors that affect the quality of the evidence is based on the design and characteristics of the studies included in the review (whether a group of studies or a single study). The case series are uncontrolled observational studies in which the quality of the evidence is automatically lowered from low to extremely low. The expert opinion is not considered a type of scientific evidence to which the factors modifying the quality of the evidence can be applied; however, it reflects the interpretation of the results of the evidence or the absence of it, depending on the expert's knowledge and experience. The GRADE process for a systematic review consists of formulating a research question, selecting the outcomes, searching for evidence, and summarizing the evidence ${ }^{23,24}$.

\section{Results}

\section{Literature search}

A total of 6,042 articles were found in the literature search. Based on the inclusion criteria, the number of articles was reduced to 17 for a brief review. Seven articles were excluded for not complying with the study designs and a total of 10 articles were assessed in this systematic review. Figure 1 describes the PRISMA flowchart for this systematic review.

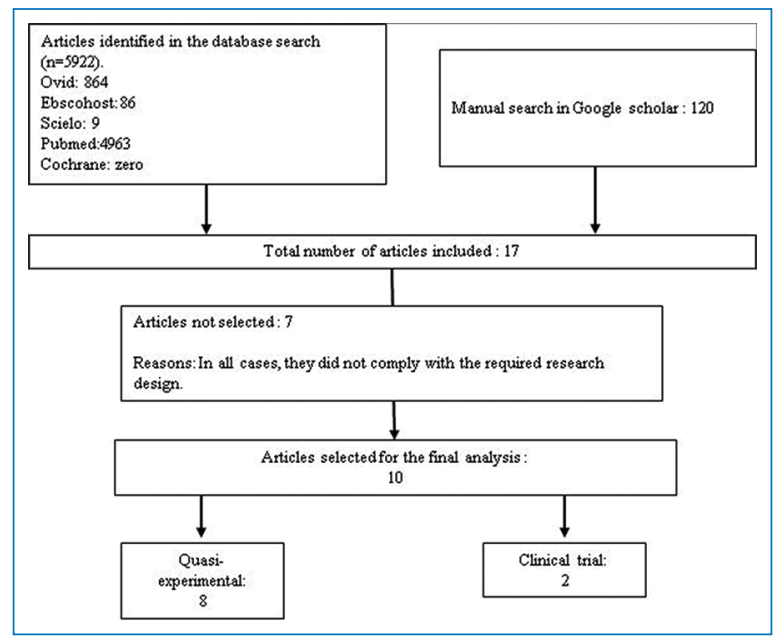

Figure 1. PRISMA flowchart.

\section{Data extraction}

The kappa concordance value for the classification of the reviewed studies was 1.0 with $p<0.05$. Of the total articles included in the final selection, two (20\%) studies had an experimental design, open and blinded cross-sectional design, while the other eight $(80 \%)$ studies used open quasi-experimental designs.

\section{Assessment of the methodological quality}

The levels of the quality of evidence according to the GRADE system were "very low" in seven articles (70\%) and "low" in three (30\%). Table 1 shows the results of the quality analysis of the selected studies.

\section{Topical treatments}

The use of topical treatments was reported in an article with a quasi-experimental design that included eight patients. Furthermore, this article aimed to determine if topical clobetasol propionate $(5 \mathrm{~g}$ at $0.05 \%$ ) applied one or two times per day for 3-7 days on the lesions (according to the severity of the symptoms) could improve the morphology of the areas with a rash and general symptoms of AP. This study reported an improvement of the patients' symptoms and did not report any complications resulting from the treatment. The authors concluded that further studies were required to confirm the findings and side effects of this study ${ }^{21}$. 


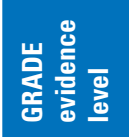

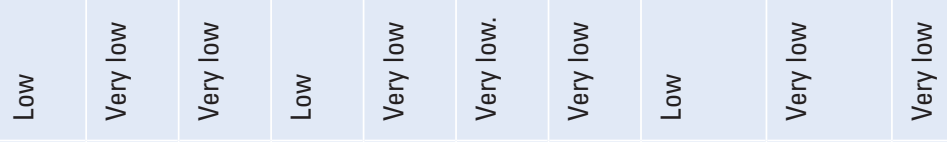

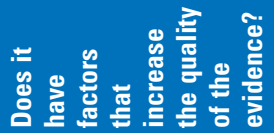

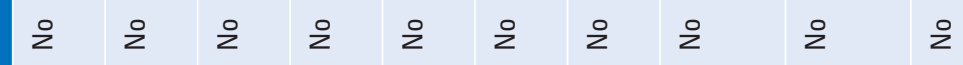
illilit

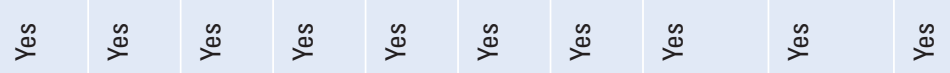

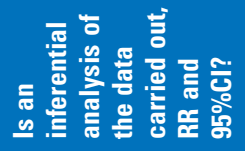

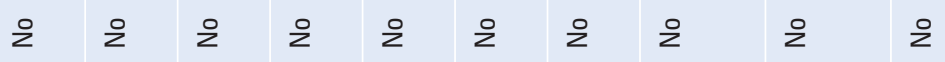
Int

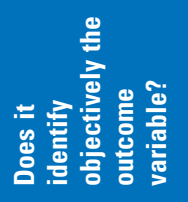

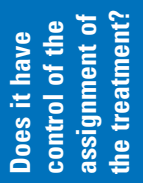

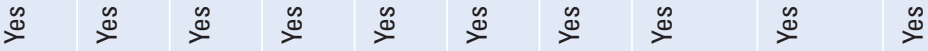
$\stackrel{\oplus}{\rightleftarrows}$
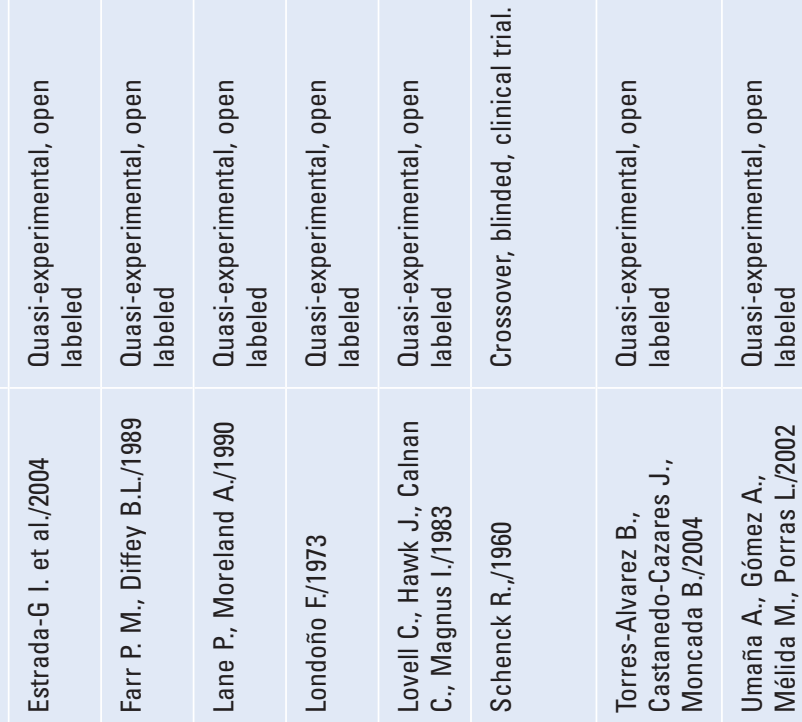


\section{Oral treatments}

Of the selected articles, three indicated thalidomide as an effective treatment for management of AP. However, each study used a different dose of thalidomide and a different quasi-experimental design, with no pre- and post-intervention inferential analyses. The outcome was assessed as the improvement in the symptoms of the patients according to the clinical assessment performed by the researcher. Moreover, two of these articles did not specify the presence or absence of complications in the patients, while the remaining indicated that the patients presented with dizziness, drowsiness, rash, laxity, "out of the body" feelings, and transient paresthesia. However, the doses of thalidomide administered to the patients varied between $50-100 \mathrm{mg}$ in children and $100-200 \mathrm{mg}$ in adults. Although there was a time gap between these studies, as they were published in 1973, 1983, and 2004 the conclusions of these studies were similar ${ }^{25-27}$.

An article compared treatments administered to patients with AP using an experimental open-label design. This study compared two groups of eight participants each; one group received $500 \mathrm{mg}$ of tetracycline three times a day for 2 months and the other group received $100 \mathrm{IU}$ of vitamin $\mathrm{E}$ per day for 4 months. Both groups showed favorable clinical results according to the clinical assessments. However, inferential analyses to identify the most effective drug were not performed. The patients who received tetracycline reported nausea, vomiting, epigastric pain, abdominal pain, and diarrhea, while the vitamin $E$ treatment group had no complications. Hence, the authors suggested using tetracycline and vitamin $\mathrm{E}$ as a therapeutic regimen for $\mathrm{AP}^{28}$.

An article showed that cyclosporine $A$ at a dose of $2.5 \mathrm{mg} / \mathrm{kg} /$ day for 6-8 months improved the clinical features of patients with AP, with no adverse reactions secondary to the treatment. These results were obtained by assessing the post-treatment clinical improvement of 19 patients using a quasi-experimental design in which 18 patients showed clinical improvement. Based on this, the authors suggested using cyclosporine $A$ as an alternative treatment in patients with $\mathrm{AP}^{29}$.

An article with a blinded cross-sectional clinical trial design indicated methoxsalen-based treatment with a regimen of $20 \mathrm{mg}$ of methoxsalen-placebo or with placebo-20 mg of methoxsalen for 4 weeks for hospitalized patients (11 patients) during the first and third week of treatment for controlling their sun exposure and in outpatients (two patients). The authors concluded that methoxsalen was not beneficial for the patients compared to placebo ${ }^{30}$.

Similarly, an article determined the effect of a pentoxifylline-based treatment regimen using a quasi-experimental design that included 10 patients. The treatment dose was $400 \mathrm{mg}$ every 8 hours for patients older than 15 years and weight $>45 \mathrm{~kg}$, and $400 \mathrm{mg}$ every 12 hours for patients aged 15 years or less or weight $<45 \mathrm{~kg}$, for 6 months in both the cases. Improvement was reported in the patients, with nausea being the only adverse reaction. The researchers concluded that this treatment is safe and effective; however, a clinical trial is required to consolidate the evidence ${ }^{31}$.

\section{Phototherapy}

An article showed results in a quasi-experimental design study that included various photodermatoses, including AP. The study independently described six patients with AP. The considered outcome was the tolerance time to sun exposure, which improved in all the patients, with itching as an adverse reaction in five of the six patients following the treatment with narrowband ultraviolet-B phototherapy at $70 \%$ of the dose of erythema determined in each patient ${ }^{32}$.

Within the treatment regimens with phototherapy, an article suggested treatment with ultraviolet-A rays and oral methoxypsoralen $(\mathrm{mg} / \mathrm{kg})$ before the application of these rays. Gel or gel with indomethacin was topically applied to the participants of this study and part of their back was covered with cotton sheets to compare the modifications that occurred in those areas at the end of the experiment. The authors did not report any adverse reactions. ${ }^{33}$.

In all the studies included in this review, the improvement was determined based on the clinical changes presented by the patient, without an analytical statistical analysis. However, for a few articles, the improvement of patients after treatment was based on the author's clinical assessment, without establishing an assessment instrument or specific objective that could determine the situation in the patient participating in the study. Table 2 shows the characteristics of the reviewed studies.

\section{Discussion}

The evidence found in this review was of low or very low quality, with similar study designs in most published 

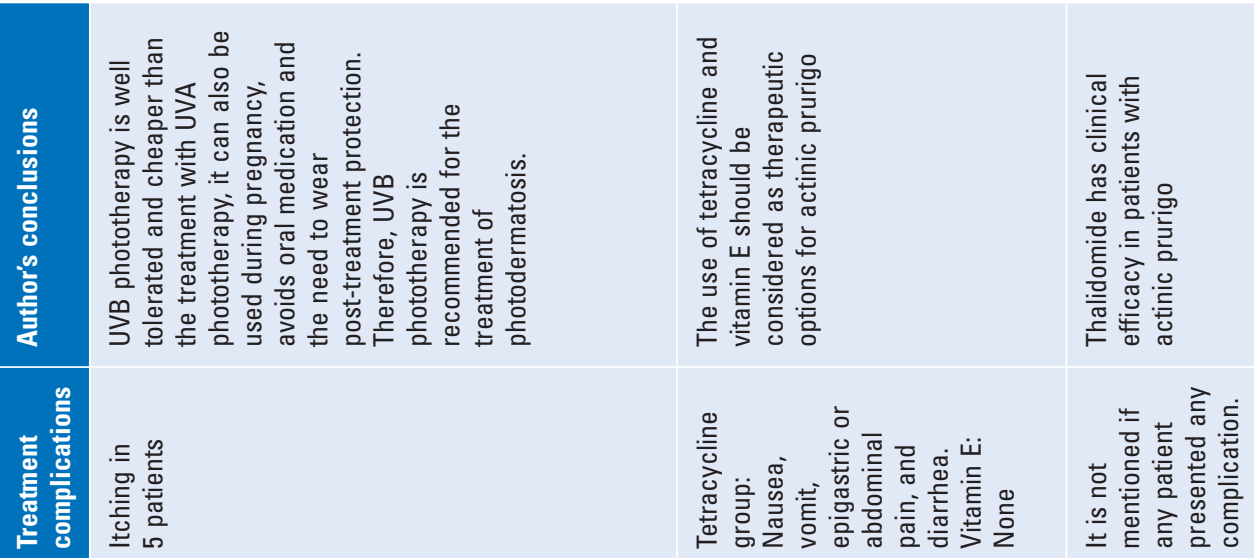

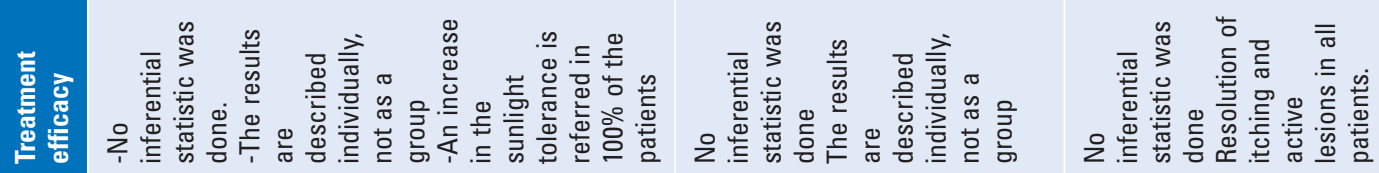

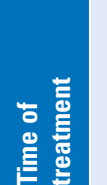

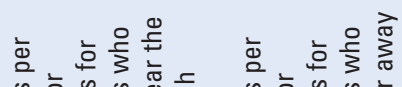

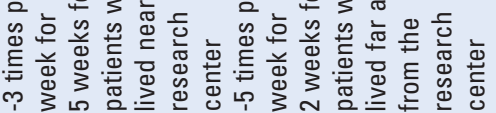
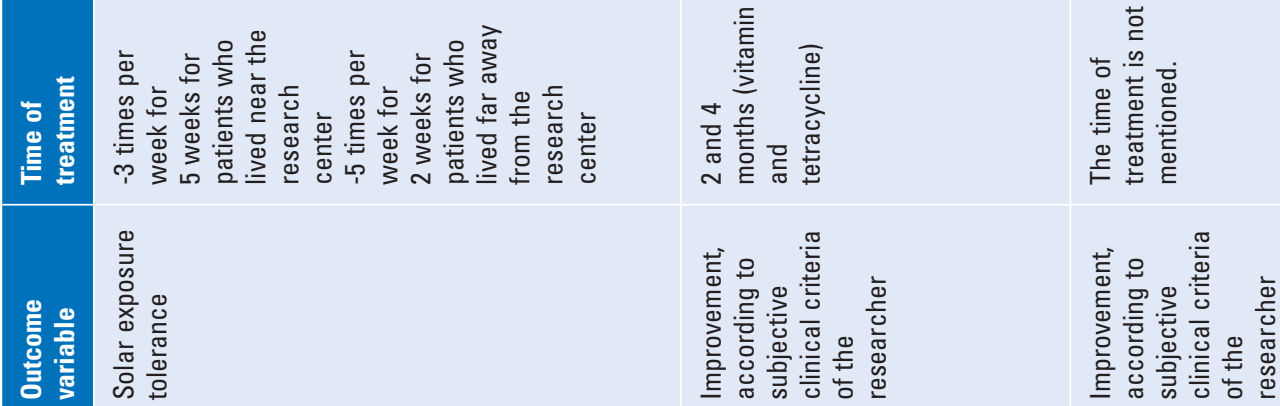

要
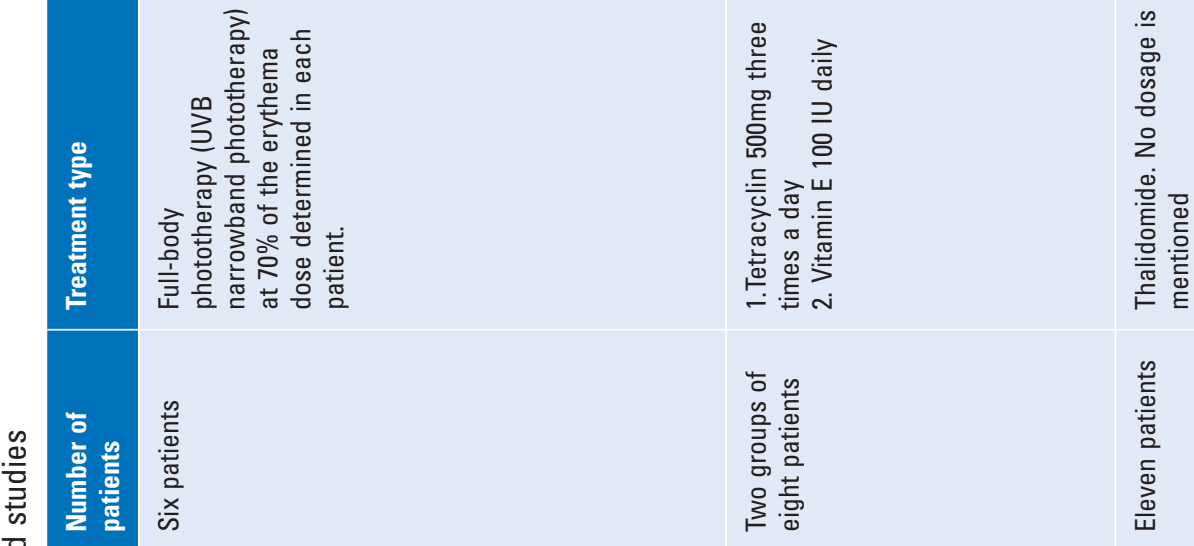

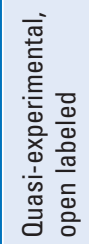
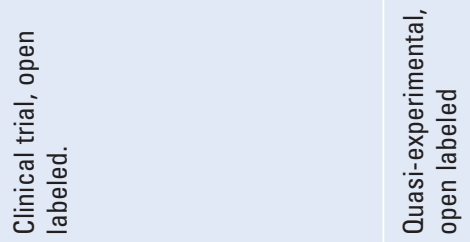

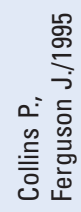

递兽

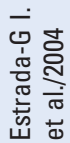



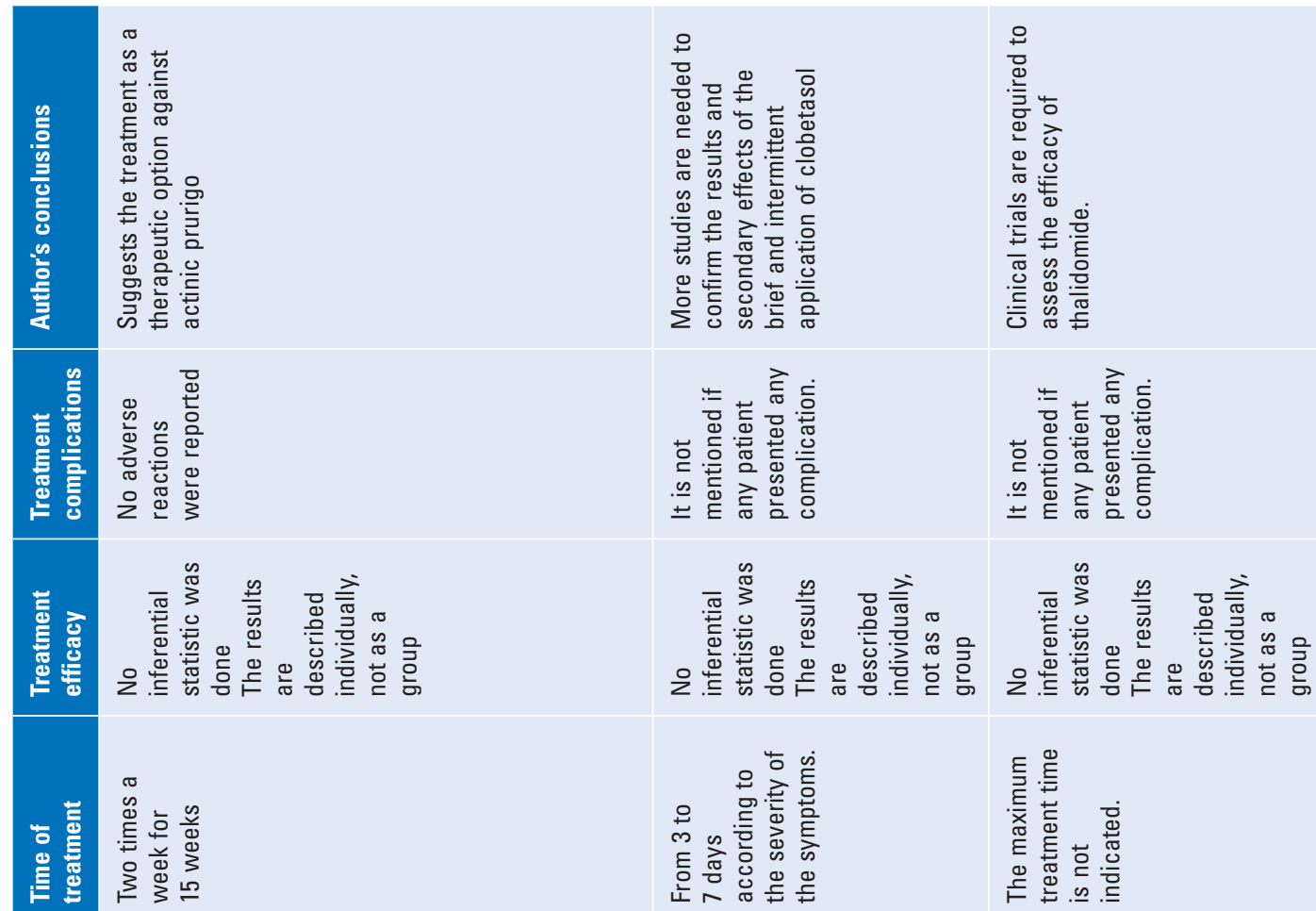

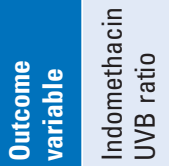
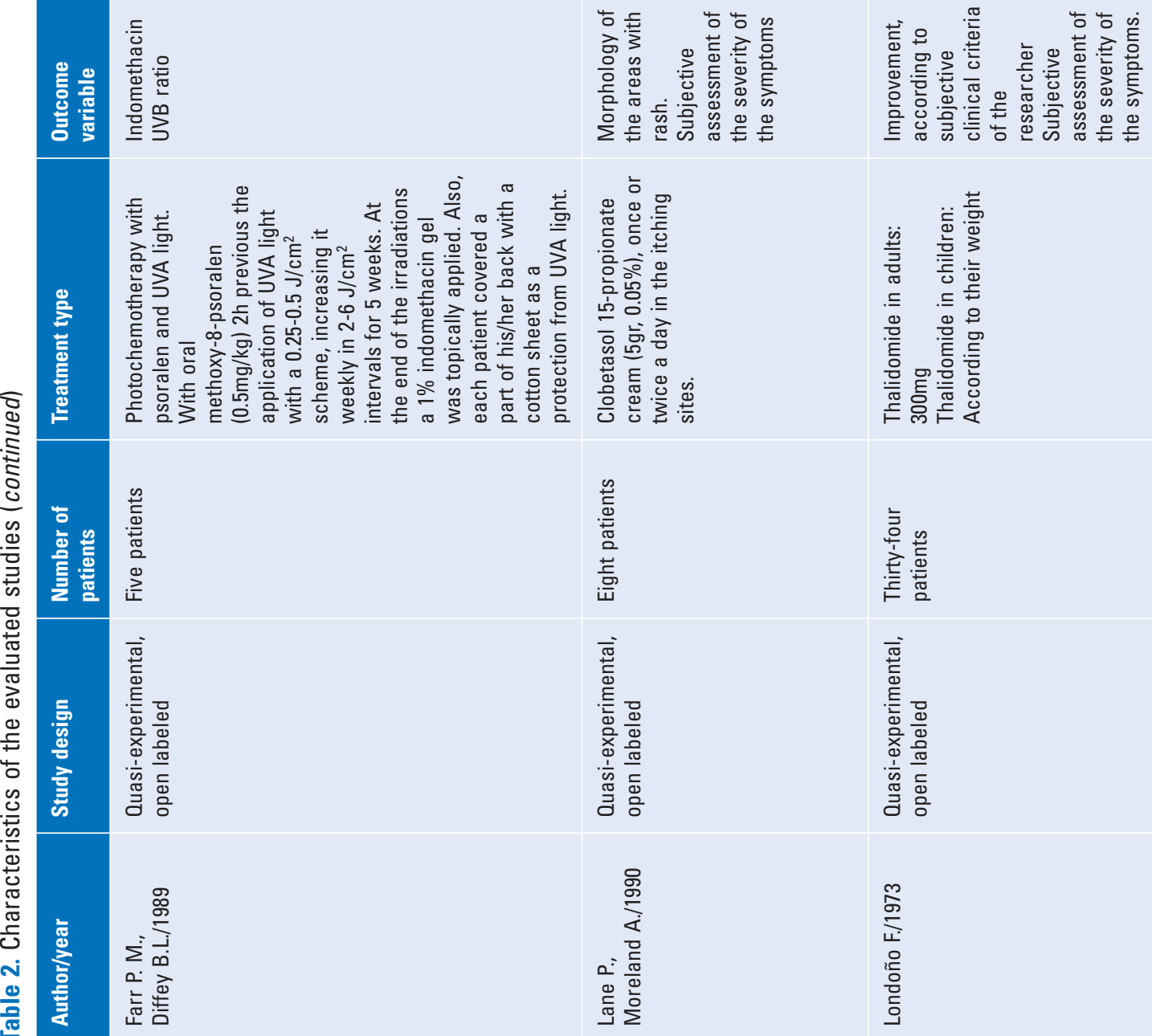

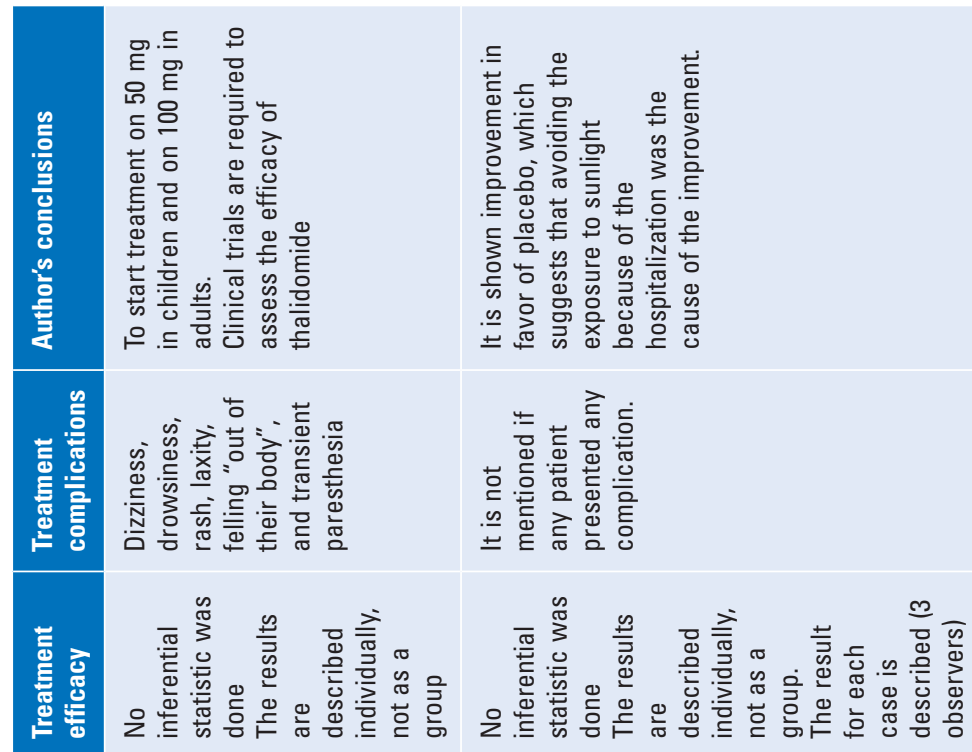

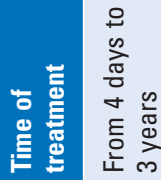
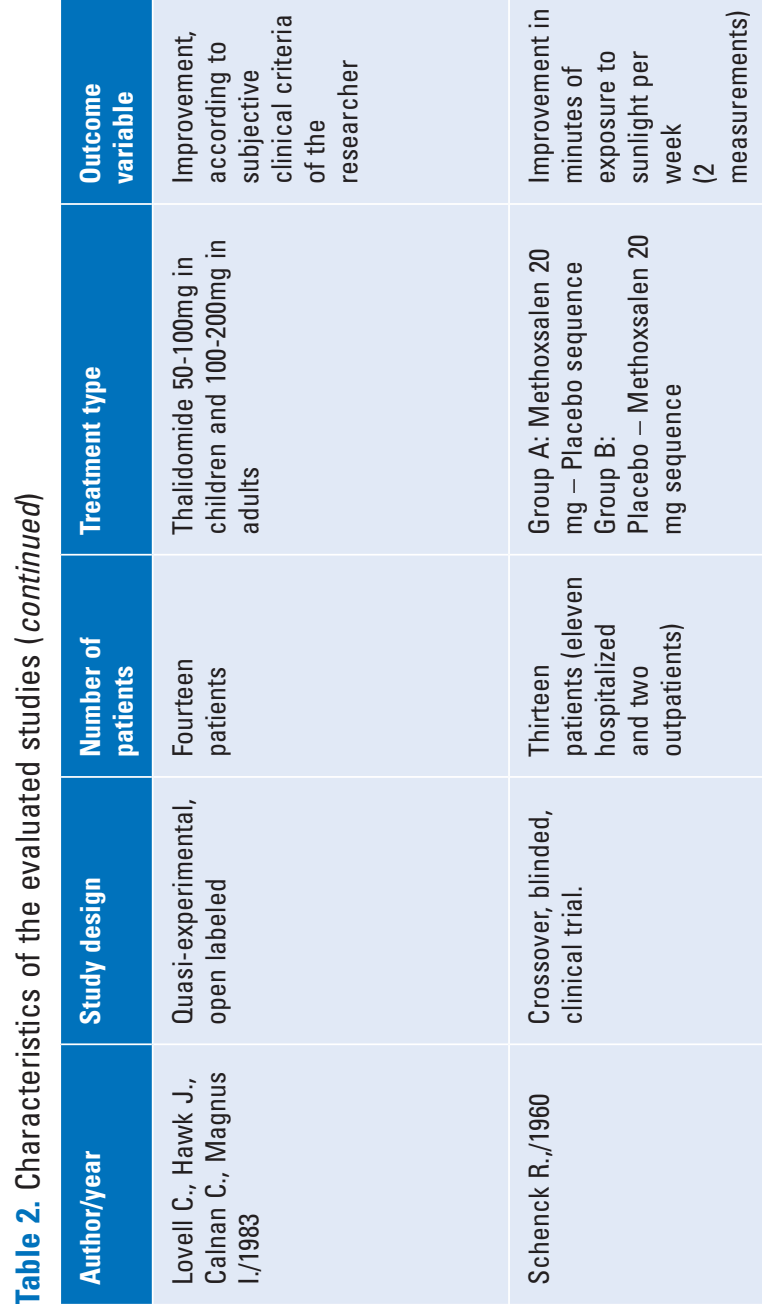

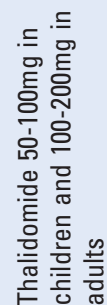
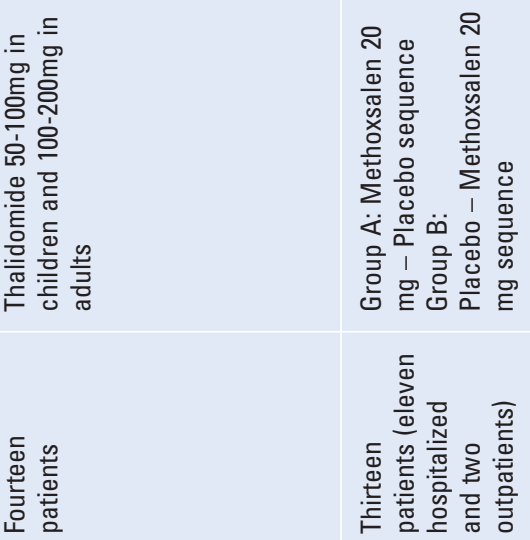

\begin{tabular}{|c|}
\hline 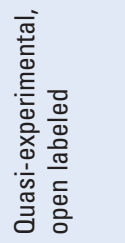 \\
\hline 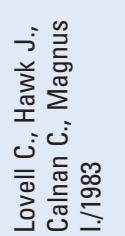 \\
\hline
\end{tabular}




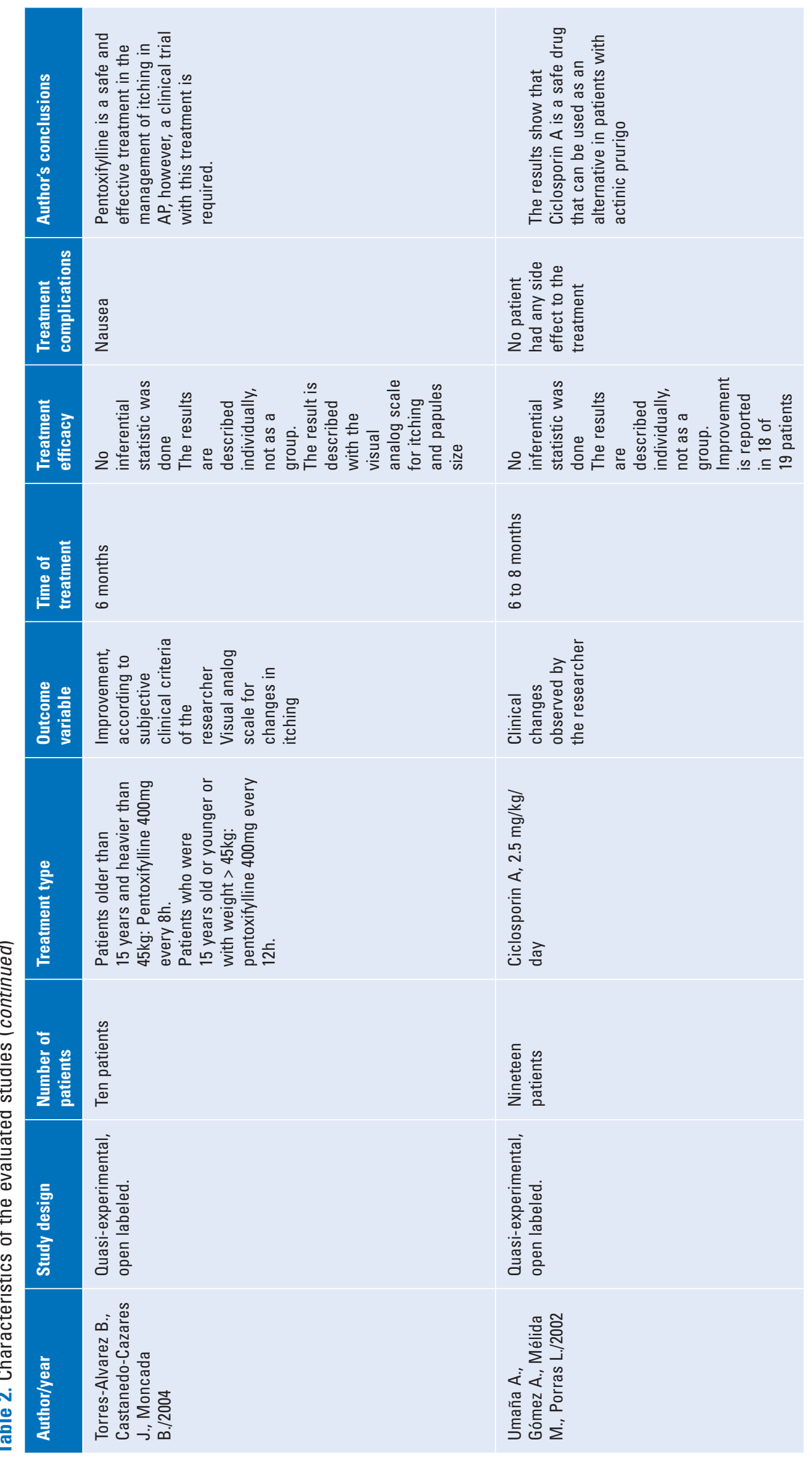


articles and only one article with a blinded clinical trial design. Although there was an important difference between the publication years, most articles used an open quasi-experimental design, which was probably due to the difficulty of acquiring evidence from the experimental study designs, since AP has a low prevalence (less than $3.5 \%$ ) and mainly presents in certain geographic areas and during specific seasons of the year ${ }^{1-3,6,8,9}$

Thalidomide, used in several doses (between 50 and $300 \mathrm{mg}$ ), was identified as a drug that improved the symptoms of patients with AP. Moreover, all the acquired evidence supported the fact that the benefits provided to the patient are more important than the adverse reactions caused by the drug, which included dizziness, drowsiness, rash, laxity, "out of the body" feelings, and transient paresthesia. This data is based on three different studies that assessed 59 patients prospectively, which is the largest group of patients that provided data supporting the decision to use thalidomide in cases of AP. An inferential analysis to determine the efficacy of the treatment was not presented in any of the cases and no follow-up of the adverse reactions to determine their remission was conducted. However, other studies reported peripheral neuropathy as an adverse reaction of thalidomide that could present up to 6 years after the discontinuation of treatment. Furthermore, studies on the assessment of the patient's nerve conduction velocity before and after treatment have indicated that if the nerve conduction velocity decreased by $40 \%$ the treatment had to be discontinued. None of the included studies considered these assessments prior to the start of treatment ${ }^{3,17,26,27,32}$.

Most of the evidence that demonstrated the efficacy of a drug in AP was supported by the presentation of clinical cases, sometimes with only one patient in the publication. An example of this is the assessment of the treatment with topical tacrolimus by González from the analysis of one patient who was administered this drug, leading the author to conclude that the use of tacrolimus ointment seemed to be an effective and safe alternative for the treatment of AP associated with the correct photoprotection measures ${ }^{6}$. However, although this publication reached the minimum qualification for being a "clinical case" design according to the GRADE quality of evidence classification, it was included as an example since it could be used as a reference for the treatment of a patient as no information with better methodological quality was available that specifically referred to the patients with AP.
Determining the efficacy from the inferential calculation of each of the studied treatments is impossible, because with the exception of thalidomide, the other studied drugs were identified in a single publication, so there were no parameters to compare the results with other studied populations. Furthermore, the evaluated outcomes were different or determined subjectively by the researcher. Similarly, the baseline characteristics of the patients who participated in the studies had heterogeneous components; therefore, it was unfeasible to conduct a meta-analysis of the data ${ }^{21,25-33}$.

The evidence observed for the treatment based on narrow band phototherapy lacked methodological strength and homogeneity in the duration and mode of the treatment. However, it quantified its outcome based on the improvement in the tolerance time to direct sun exposure and although the baseline tolerance to sunlight of the participants varied between 10 minutes and 1 hour, the results indicated an improvement in tolerance ranging between 3 hours and 1 day, and this effect was maintained for 4 months. However, the patients showed heterogeneity at the start the study and were administered different doses of systemic treatment or phototherapy. After obtaining the clinical results, no inferential analysis was performed; hence, despite the support of other studies for the use of this treatment, no evidence classified as "good" according to the GRADE system was found specifically for the treatment of patients with $\mathrm{AP}^{1,15,32}$.

The evidence obtained for other treatments, described as secondary options to the use of thalidomide, such as steroids, pentoxifylline, vitamin E, and tetracycline, were of low or extremely low level of evidence according to GRADE system. These treatment options maintained the inconsistencies previously mentioned, like a small number of studied patients, subjective outcomes based on the researcher's assessment, and no inferential analysis of the results. However, conclusions supported the use of these drugs, described as secondary options, following improvement of the patients' symptoms. This supported our inference and reflected the difficulty of acquiring a group of patients to conduct study designs that provided a higher quality evidence by applying a rigorous selection criteria and using a larger sample size to assess the efficacy of each of the proposed treatments for the care of patients with AP, from the clinic to impact on their life quality $21,22,25-33$.

\section{Conclusion}

Based on the low prevalence, geographic location, seasonality of the appearance of the disease, and 
being an acquired photodermatosis, we concluded that no publications, which were classified as high or extremely high-quality evidence, were available, specifically for AP, since the general therapeutic measures were shared with other pathologies of this group. Moreover, gathering a sufficient number of patients for a complete sample size calculated in a probabilistic manner for the formation of at least two groups was difficult. This study demonstrated the need to conduct randomized clinical trials with a rigorous methodology to generate a greater amount of better-quality information, which supported a better and more adequate therapeutic decision-making based on reliable evidence.

Hence, dermatological centers that receive patients with AP can facilitate the development of good quality studies conducted by clinical experts.

\section{Acknowledgments}

To Dr. Felix Guillermo Márquez Celedonio for his support during this work.

\section{Funding sources}

All expenses were borne by the investigators.

\section{Conflicts of interest}

The authors declare no conflicts of interest

\section{Ethical disclosures}

Protection of human and animal subjects. The authors declare that no experiments were performed on humans or animals for this study.

Confidentiality of data. The authors declare that no patient data appear in this article.

Right to privacy and informed consent. The authors declare that no patient data appear in this article.

\section{References}

1. Lestarini D, Khoo LSW, Goh CL. The clinical features and management of actinic prurigo: A retrospective study. Photodermatol Photoimmunol Photomed. 1999;15(5):183-7.

2. Ruiz Beguerie J. Prurigo Actínico. Dermatol Argent. 2013;19(4):251-9.

3. Ross G, Foley P, Baker C. Actinic prurigo. Photodermatol Photoimmunol Photomed. 2008;24(5):272-5.

4. Crouch R, Foley P, Baker C. Actinic prurigo: a retrospective analysis of 21 cases referred to an Australian photobiology clinic. Australas J Dermatol. 2002;43(2):128-32.

5. Cuevas-Gonzalez J, Borges-Yañez S, Vega-Memije M, Rodriguez-Lobato $E$. Risk factors associated with actinic prurigo: A case control study. An Bras Dermatol. 2017:92(6):774-8.
6. González Carrascosa Ballesteros M, De La Cueva Dobao P, Hernanz Hermosa JM, Chavarría Mur E. Tratamiento del prúrigo actínico con tacrolimus al 0,1\%. Med Cutan Ibero Lat Am. 2006;34(5):233-6.

7. Lestarini D, Khoo LSW, Khoo LSW, Goh CL. The clinical features and management of actinic prurigo: A retrospective study. Photodermatol Photoimmunol Photomed. 1999;15(5):183-7.

8. Salazar A. Prurigo actínico en la niñez. Dermatol Pediatr Lat. 2005;3(3):193-200.

9. Zuloaga-salcedo S, Castillo-vazquez M, Vega-memije E, Arellano-campos O, Rodriguez-perez JM, Perez-Hernandez N, et al. Class I and class II major histocompatibility complex genes in Mexican patients with actinic prurigo girl successfully treated with systemic. $\mathrm{Br} \mathrm{J}$ Dermatol. 2007;156:1074-5

10. Gomez A, Umana A, Trespalacios AA. Immune responses to isolated human skin antigens in actinic prurigo. Med Sci Monit [Internet]. 2006;12(3):BR106-13. Available from: http://ovidsp.ovid.com/ovidweb. cgi?T=JS\&PAGE=reference\&D=med5\&NEWS=N\&AN=16501416

11. Sandoval M, Escaffi maria jose. Prurigo actínico. Rev Chil Dermatol. 2011;16(1):232.

12. Snyder M, Turrentine JE, Cruz PD. Photocontact Dermatitis and Its Clinical Mimics: an Overview for the Allergist. Clin Rev Allergy Immunol. 2018;1-9.

13. Castanedo-cazares JP. Actinic Prurigo [Internet]. medscape. 2017 [cited 2018 Nov 18]. p. 1-17. Available from: https://emedicine.medscape.com/ article/1120153

14. Morison WL. Photoprotection by clothing. Dermatol Ther. 2003;16(1):16-22

15. Hojyo-Tomoka MT, Vega-Memije ME, Cortes-Franco R, Domínguez-Soto $\mathrm{L}$. Diagnosis and treatment of actinic prurigo. Dermatol Ther. 2003;16(1):40-4.

16. Rosen CF. Topical and systemic photoprotection. Dermatol Ther. 2003;16(1):8-15.

17. Wu JJ, Huang DB, Pang KR, Hsu S, Tyring SK. Thalidomide : dermatological indications, mechanisms of action and side-effects. 2005;254-73.

18. $\mathrm{Ng} \mathrm{JCH}$, Foley PA, Crouch RB, Baker CS. A case of severe actinic prurigo successfully treated with thalidomide. Australas $\mathrm{J}$ Dermatol. 2001;42(3):192-5.

19. Hassan I, Dorjay K, Anwar P. Thalidomide in Dermatology : Revisited Structure of Thalidomide. Indian J Dermatol. 2015;60(2):213.

20. Naka F, Makkar H, Lu J. Teledermatology: Kids are not just little people [Internet]. Vol. 35, Clinics in Dermatology. Elsevier B.V.; 2017. 594-600 p. Available from: http://dx.doi.org/10.1016/j.clindermatol.2016.07.007

21. Lane PR, Moreland AA, Hogan D. Treatment of Actinic Prurigo With Clobetasol 17-Propionate. arch dermatol. 1990;126:1211-3.

22. Jong CT, Finlay AY, Pearse AD, Kerr AC, Ferguson J, Benton EC, et al. The quality of life of 790 patients with photodermatoses. Br J Dermatol. 2008:159(1):192-7.

23. Neumann I, Pantoja T, Peñaloza B, Cifuentes L, Rada G. El sistema GRADE: un cambio en la forma de evaluar la calidad de la evidencia y la fuerza de recomendaciones. Rev médica Chile [Internet]. 2014;142(5):630-5. Available from: http://www.scielo.cl/scielo.php?script=sci_arttext\&pid=S0034-98872014000500012\&lng=es\&nrm=iso\&t|$\mathrm{ng}=\mathrm{es}$

24. Sanabria A, Rigau D, Rotaeche R, Selva A. Atención Primaria Sistema GRADE : metodología para la realización de recomendaciones para la práctica clínica. Atencion. 2015;47(9):48-55.

25. Lovell CR, Hawk JLM, Calnan CD, Magnus IA. Thalidomide in actinic prurigo. Br J Dermatol. 1983;108(4):467-71.

26. Estrada-G. I, Garibay-Escobar A, Núñez-Vázquez A, Hojyo-Tomoka T, Vega-Memije $\mathrm{E}$, Cortés-Franco $\mathrm{R}$, et al. Evidence that thalidomide modifies the immune response of patients suffering from actinic prurigo. Int J Dermatol. 2004;43(12):893-7.

27. Londoño F. Thalidomide in the Treatment of Actinic Prurigo. Int J Dermatol. 1973;12(5):326-8.

28. Durán MM, Ordoñez CP, Prieto JC, Bernal J. Treatment of actinic prurigo in Chimila Indians. Int J Dermatol. 1996;35(6):413-6.

29. Umaña A, Gómez A, Durán MM, Porras L. Lymphocyte subtypes and adhesion molecules in actinic prurigo: observations with cyclosporin $A$. 2002;139-45.

30. FARR PM, DIFFEY BL. Treatment of actinic prurigo with PUVA: mechanism of action. Br J Dermatol. 1989;120(3):411-8.

31. Torres-Alvarez B, Castanedo-Cazares JP, Moncada B. Pentoxifylline in the treatment of actinic prurigo: A preliminary report of 10 patients. Dermatology. 2004;208(3):198-201.

32. Collins P, Ferguson J. Narrow-band UVB (TL-01) phototherapy: an effective preventative treatment for the photoderrnatoses. Br J Dermatol [Internet]. 1995 Apr;132:956-63. Available from: http://www.ncbi.nlm.nih. gov/pubmed/603975

33. Schenck RR. Controlled trial of methoxsalen in solar dermatitis of chippewa indians. J Am Med Assoc. 1960;172(11):1134-7. 